\title{
An Adaptive User Interface for an E-learning System by Accommodating Learning Style and Initial Knowledge
}

\author{
Didik Hariyanto \\ Department of Electrical Engineering Education, Faculty of \\ Engineering, Yogyakarta State University, Indonesia. \\ Institute of Vocational Education, Faculty of Education, \\ Dresden University of Technology, Germany. \\ didik_hr@uny.ac.id; didik.hariyanto@tu-dresden.de
}

\author{
Thomas Köhler \\ Institute of Vocational Education, Faculty of Education, \\ Dresden University of Technology, Germany. \\ thomas.koehler@tu-dresden.de
}

\begin{abstract}
There is a conception among researchers that every student has his or her own learning style preferences. One student cannot be treated as same as the other students. A specific strategy is required to provide a learning environment that is suitable for different students' preferences. In the context of technology-enhanced learning, it is urgently necessary to design an adaptive e-learning system based on multiple learning criteria. This paper presents the design of a user interface for an e-learning system that can adapt to multiple learning styles and initial knowledge levels. To evaluate the design concept, an application has been developed and then tested based upon a functional test approach. As a result, it was found that the elearning system could react as intended, presenting the learning material and navigation components based on both the learning styles and initial knowledge of the students.
\end{abstract}

Keywords-Adaptive E-Learning; User Interface; Learning Style; Knowledge Level

\section{INTRODUCTION}

Nowadays, e-learning systems are in use in many schools. Since a system is needed that easily handles many users at the same time and can be accessed remotely, most e-learning systems are developed based upon web forms. In web-based education, two challenging issues should be considered: adaptivity and intelligence [1].

This paper will focus on adaptivity in an e-learning system. An adaptive e-learning system is a type of software system that can provide content to the learner and adjust it to suit the needs of a particular learner based on the learner's characteristics [2, 3]. Since students have many differences, adaptive e-learning is the key to overcoming these differences and making learning suited for all [4]. Adaptivity is one of the most important keys in dealing with differences among learners. Kareal et al. suggested an adaptivity rule as an essential part of an effective educational process and stated that it should be implemented in e-learning systems [5]. Thus, adaptive e-learning has the capability to create a suitable environment and content based on different students' preferences to improve the effectiveness of the learning process.
One of the parameters used as a variable for adaptation in e-learning systems is the student's learning style. Since every person has a unique learning style [6], a model is needed to distinguish student learning styles. Many models have been developed [7-13]. The most well-known learning style in engineering education is the Felder-Silverman Learning Style Model (FSLSM) [14, 15]. Felder and Silverman divided their model into four dimensions: active-reflective, sensing-intuitive, visual-verbal, and sequential-global [13].

Many researchers have studied adaptive e-learning systems based on a single criterion, such as learning style, cognitive style, knowledge state, or students behavior; however, few studies have considered multiple learning criteria. The main objective of this paper is to provide a design for a user interface for an e-learning system that adapts to multiple learning criteria: students' learning style and initial knowledge. First, the characteristics of the Felder-Silverman learning style and the concept of knowledge used in this study are explored and understood. Then, the work continues with the development of a set of rules for how the user interface should act in response to different combinational inputs of learning style and initial knowledge of the students. To prove the concept, an application has been developed based on the proposed design. Then an evaluation based upon functional test strategy was performed by applying some possible test cases.

\section{FELDER AND SILVERMAN LEARNING STYLE MODEL}

One of the most widely used learning styles in engineering education context is the model constructed by Felder and Silverman. The Felder and Silverman Learning Style Model (FSLSM) classified an individual learning style preference across four dimensions divided into two categories [13]. Table I describes the dimensions of the learning styles and the characteristics of each learning style. 
TABLE I. FELDER-SILVERMAN LEARNING STYLE CHARACTERISTICS

\begin{tabular}{|c|c|l|}
\hline Dimension & $\begin{array}{c}\text { Type of } \\
\text { Learning } \\
\text { Style }\end{array}$ & \multicolumn{1}{c|}{ Characteristics } \\
\hline \multirow{2}{*}{ Processing } & Active & $\begin{array}{l}\text { Prefer to learn by doing, experimentation, } \\
\text { and working in groups. }\end{array}$ \\
\cline { 2 - 3 } Perception & Reflective & $\begin{array}{l}\text { Prefer to learn by thinking and observing } \\
\text { problems for a moment and working } \\
\text { alone. }\end{array}$ \\
\cline { 2 - 4 } & Intuitive & $\begin{array}{l}\text { Prefer facts, data, and experimentation } \\
\text { and patient with details. } \\
\text { and bored with details. }\end{array}$ \\
\hline \multirow{2}{*}{ Input } & Visual & $\begin{array}{l}\text { Prefer to perceive materials in a visual } \\
\text { form, such as pictures, diagrams, } \\
\text { flowcharts, demonstrations, videos. }\end{array}$ \\
\cline { 2 - 4 } & Verbal & $\begin{array}{l}\text { Prefer to perceive materials in a verbal } \\
\text { form, such as texts, audios. }\end{array}$ \\
\hline \multirow{2}{*}{ Understanding } & Sequential & $\begin{array}{l}\text { Prefer to process information } \\
\text { sequentially. }\end{array}$ \\
\cline { 2 - 3 } & Global & \begin{tabular}{l} 
Prefer to grasp the whole picture first. \\
\hline
\end{tabular} \\
\hline
\end{tabular}

\section{THE CONCEPT OF KNOWLEDGE}

Hunt conducted a study to determine the definition of knowledge and found an appropriate way to measure it [16]. He concluded that knowledge has generally been defined as beliefs that are not only correct but also should be justified. Pask [17] described in [18] that knowledge is revealed only by the ability to 'respond correctly to the contingencies or problems presented'. Hunt added that a correct or incorrect answer from a person simply interpreted between knows and does not know on a particular question. To measure the correctness of an answer, there is a 'set of rules' to be created. A multiple-choice test may be considered a 'set of rules', and the score produced could be operationally defined as knowledge $[16,19,20]$. To measure knowledge on a particular topic, the test items must represent the topic. When questions on a particular topic are answered correctly, it means that the person who took that test has knowledge on that topic, and when the answer is incorrect, it indicates that he/she has no knowledge on that topic.

\section{DESIGN OF ADAPTIVE USER INTERFACE}

\section{A. Concept of Adaptation}

With regard to the adaptation theory, Brusilovsky said that the important question regarding any type of adaptive system is what can be adapted [1]. He explained that two essential items should be tailored in an adaptive system, the content presented (content-level adaptation) and the links between pages (linklevel adaptation). He referred to these two levels of adaptation as adaptation in presentation and adaptation in navigation support, respectively.

Adaptation in presentation is how the system can automatically adjust the content presented on each page of the adaptive system based on student preferences. The concept of this type of adaptation is to provide the same information in different ways [21]. Various techniques are available to accomplish this goal:
- Media type based: The content of the adaptive system could be presented with various media types. Some students may prefer to absorb information in visual form (pictures, diagrams, flowcharts, videos), while others may prefer it in verbal form (text, audio).

- Learning object based: The information could be provided in different learning objects; some students may prefer to study through doing many examples rather than through definition, while others prefer the other method.

Adaptation in navigation support is the ability of the adaptive system to provide suitable learning paths to meet a variety of student needs. To enable the navigation components could adapt to personalized learning, the following methods can be used [22, 23]:

- Direct guidance: This is the simplest technique used in adaptive systems. This type of navigation works based on the concept of sequential learning mechanisms. There is a 'next' or 'continue' link or button to navigate within the learning environment.

- Link sorting: The idea of link sorting begins with sorting all the links on a particular page in the adaptive system. The sorting process can be done based on the most relevant information as the top sort related to the goal of the learning.

- Link hiding: The technique of link hiding can be provided by hiding, removing, or disabling navigation links or buttons related to pages that are inappropriate or irrelevant to the learning topic.

- Link annotation: The concept of this technique involves presenting link anchors through some form of visual cues for the relevant information. These annotations may be provided with different colors, icons, arrows, or font-sizes.

\section{B. Set of Rules}

To build the adaptive user interface design for an e-learning system, the first step is defining the set of rules to determine which learning resources are more appropriate or relevant to a particular learning style. Based on the theoretical descriptions of Felder-Silverman learning styles and some practical studies [24-27], the learning objects and learning media formats of the system are described in Table II and III.

Table II lists the objects used in the learning environment related to the learning object-based adaptation method, while Table III associates the media utilized in the learning environment based on the learning media type-based adaptation method. Table II shows the learning objects associated with two dimensions according to Felder-Silverman: active-reflective and sensing-intuitive dimensions. There are five learning objects (simulation, example, synthesis, lesson objective, and case study) that correspond to those dimensions. Table III lists the learning media formats associated with the visual-verbal dimension. Visual preference is represented by image, video, and animation media, while verbal preference is represented by text, audio, and video formats. 
TABLE II. LEARNING OBJECTS IN THE ACTIVE-REFLECTIVE AND SENSING-INTUITIVE DIMENSIONS.

\begin{tabular}{|l|c|c|c|c|}
\hline \multicolumn{1}{|c|}{ Learning Objects } & Active & Reflective & Sensing & Intuitive \\
\hline Simulation & $\sqrt{ }$ & & $\sqrt{ }$ & \\
\hline Example & $\sqrt{ }$ & & $\sqrt{ }$ & \\
\hline Synthesis & $\sqrt{ }$ & & & $\sqrt{ }$ \\
\hline Lesson Objective & & $\sqrt{ }$ & & $\sqrt{ }$ \\
\hline Case Study & & $\sqrt{ }$ & & $\sqrt{ }$ \\
\hline
\end{tabular}

TABLE III. LEARNING MEDIA FORMATS IN THE VISUAL-VERBAL DIMENSION.

\begin{tabular}{|l|c|c|}
\hline \multicolumn{1}{|c|}{ Learning Media Formats } & Visual & Verbal \\
\hline Text & & $\sqrt{ }$ \\
\hline Image & $\sqrt{ }$ & \\
\hline Audio & & $\sqrt{ }$ \\
\hline Video & $\sqrt{ }$ & $\sqrt{ }$ \\
\hline Animation & $\sqrt{ }$ & \\
\hline
\end{tabular}

To regulate the sequential-global dimension, the concept of adaptation in navigation support is used to determine the appropriate learning path in the system. Since the sequential learner prefers to learn by orderly thinking or step-by-step learning, a suitable way to present the navigation is by using the direct guidance method where there is a link or button to explore the learning environment. The student can navigate one step forward to the next page using the 'next' button or jump to the previous page using the 'back' button. To deal with the global learner, the appropriate technique is the link hiding method. The link hiding method gives the ability to manage which link or button should be shown or hidden in the navigation components.

\section{Design of Layout}

\section{1) Base Layout}

After establishing the set of rules for how the content is to be presented and how the navigation components will be provided, the work of layout design is conducted to provide full insight into the presentation layout framework. Fig. 1 shows the base layout of the system, which consists of the following areas:

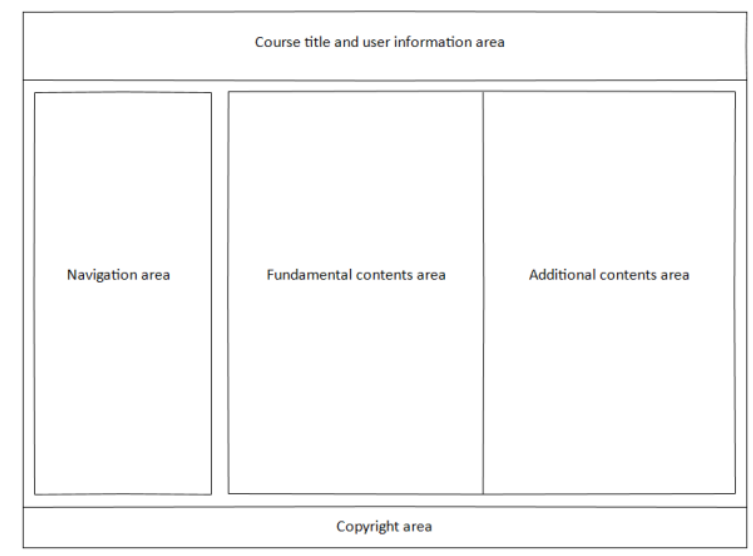

Fig. 1. The layout framework of the learning environment
- The course title and user information area. This area is used to present the information regarding the adaptive system, subject title, and personal and academic data on the user.

- The navigation area. This area contains the links representing the units and sub-units of the course. The links in this area can be used to obtain the outline of the course. The links for the learning style preference and pre- and post-test results are also provided in this area.

- The fundamental content area. This area is allocated to the center of the screen for presentation of the learning materials. There are two content areas, one to display the fundamental content and the second one to present additional content that will explain the next point. For the fundamental content area, since not all the learning materials can be described in only one media format. Thus, this area can present the learning materials in all media types needed to provide easy and good understanding for the students.

- The additional content area. Regarding the student's style of learning, this area, located on the right side of the screen, presents additional information in particular media formats. For the visual learner, this area will provide the learning material in more visual media formats rather than in verbal media formats. In contrast, for the verbal learner, this area will show more verbal media types rather than visual media types. At the top of this area are also provided buttons representing the active-reflective and sensing-intuitive dimension of the Felder-Silverman learning styles. Using the link hiding method, the buttons will be shown or hidden depending on the student's style of learning. When one of the buttons is clicked, an additional window will appear and provide the extra information through particular learning activities.

- The copyright area. It is positioned at the bottom and provides brief information about the copyright of the system and how to contact the administrator.

\section{2) Knowledge Level Navigation Layout}

To determine the initial knowledge of the students, the students must take a pre-test prepared by the system. The questions on the pre-test represent all units in the course. Based on the result of the pre-test, the system decides which learning material will be displayed in the learning environment. The algorithm processes are based on the following cases: if the result of the pre-test on a particular unit equals or exceeds the reference grade set up by the teacher, it means that the student is competent enough in that unit, so the link will be hidden. If the result is lower than the standard grade, it means that the student is not competent in that unit and needs to learn it, so the link will be shown, and the student can access the learning materials. In these cases, the link hiding method is used to manipulate the showing or hiding of the unit link. Fig. 2 and Fig. 3 show two different cases of knowledge navigation. Fig. 2 shows the case where the results of the pre-tests in all units do not pass the reference grade, while Fig. 3 illustrates the case 
where one of the links is hidden because the pre-test in a particular unit has a good score.

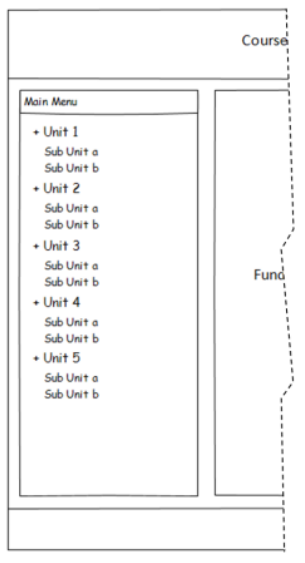

Fig. 2. Links for all units (Units 1 , $2,3,4,5)$ are shown

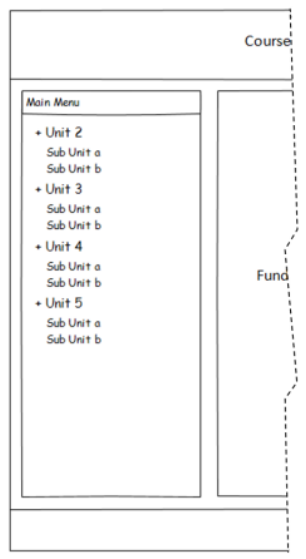

Fig. 3. Links for Units 2, 3, 4, and 5 appear, but Unit 1 is hidden

\section{3) Sequential-Global Learning Component Layout}

A sequential type of learner prefers to absorb information in linear steps with one point on each page. To deal with this style of learning, 'prev' and 'next' buttons to navigate through the learning material. The 'next' button is used to jump to the next material, while the 'prev' button returns to the previous material. Moreover, the main menu shows only the links for the units instead of displaying the sub-units in detail. Fig. 4 depicts the layout design for the sequential learning style.

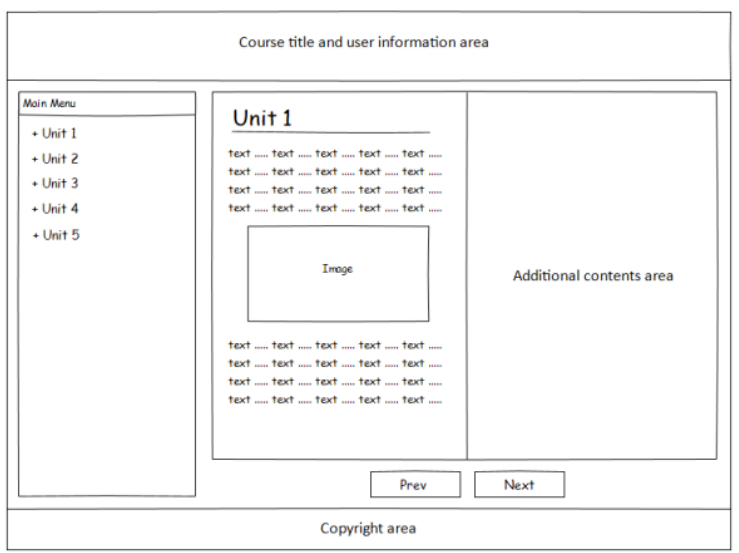

Fig. 4. Sequential learning style layout

The global learner tends to think holistically, obtaining an overview of the course before jumping into the material in detail. Fig. 5 shows the layout design for the global learner type. The system provides links related to all units and subunits to give a brief overview of the course. There is also a short explanation for each unit to give a comprehensive view of all units provided.

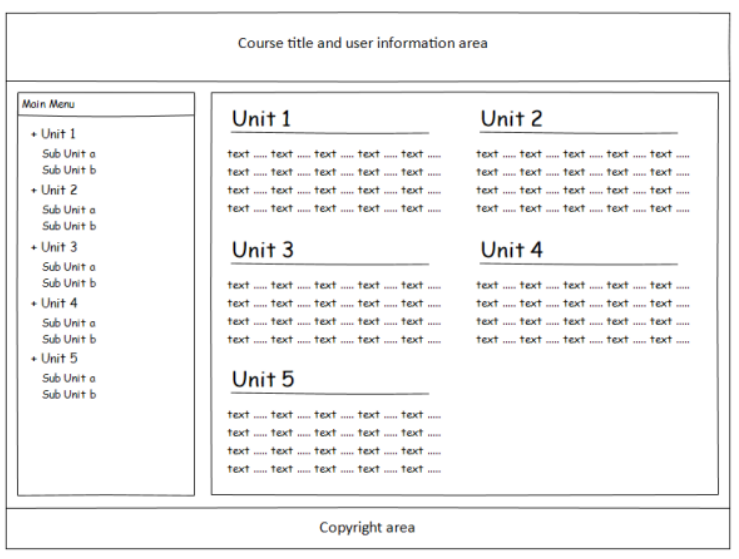

Fig. 5. Global learning style layout

\section{4) Visual-Verbal Learning Component Layout}

Fig. 6 and Fig. 7 depict the different layout designs for the visual and verbal learning styles. For the visual learner, the learning material is provided mostly using visual media such as images, video, and animation, while for the verbal learner, the learning material is provided by text, audio, and video.

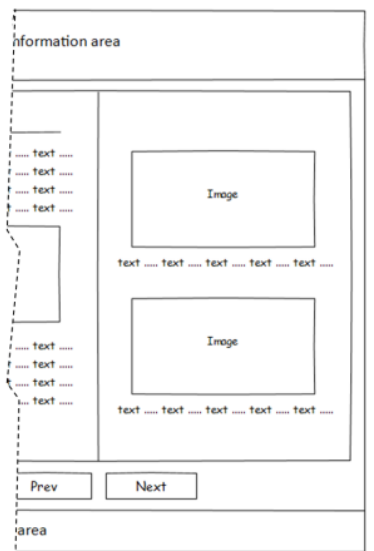

Fig. 6. Visual learning style layout

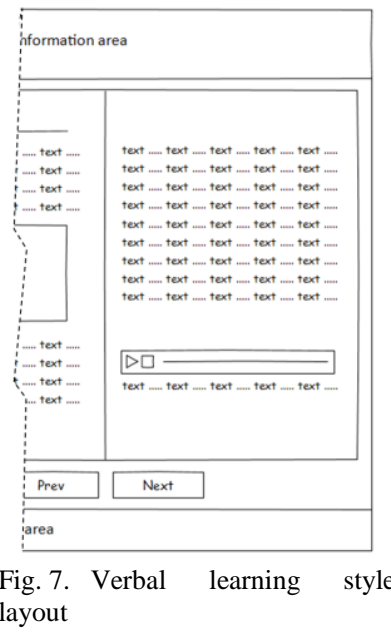

\section{5) Active-Reflective and Sensing-Intuitive Learning} Component Layout

To accommodate the active-reflective and sensing-intuitive dimensions of the Felder-Silverman learning styles, additional buttons are located at the top of the additional content area. The buttons are correlated with the learning activities provided in the set of rules listed in Table II. For the active and sensing learner, for example, buttons for simulation, example, and synthesis will be visible. The user can access content by clicking a button, which will open a new window that provides the learning material through a particular learning activity. 


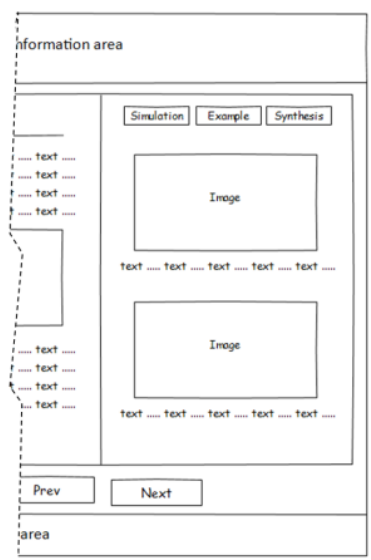

Fig. 8. Active-reflective and sensing-intuitive learning style layout

\section{Evaluation Using Functional-BAsed Test ApPROACH}

To assess the performance of the proposed adaptive user interface approach, an evaluation was conducted in the context of software testing. Software testing is a critical element in software development to ensure that there are no bugs in the software and that the software can work as designed [28]. Williams mentioned that one of the basic tests for software testing is black box testing [29]. Luo referred to black box testing as functional testing [30]. This test focuses only on the outputs generated by the system with certain inputs. It test ignores the internal mechanism of a system or component [31]. The functional test was administered by trying some combinations of learning styles and knowledge levels as input. Since four dimensions of the Felder-Silverman learning styles are used in this approach, there are 16 possible learning styles that should be prepared as scenario tests. To provide a good understanding of how the system could work as designed so that the interface can change automatically by giving different learning style and knowledge level inputs, we will explain two example test cases in more detail.

\section{A. Example Test Case 1}

A student takes the learning style questionnaire and pre-test provided by the system, and the results of the questionnaire and pre-test are formulated as follows:

- The learning style is active-sensing-visual-sequential.

- The result of the pre-test indicates that the student score is lower than the standard grade set up by the teacher for each unit; in other words, the student is not competent enough in all units provided by the course.

After entering the aforementioned input test scenario into the system, the interface of the system can adapt as shown in Fig. 9.

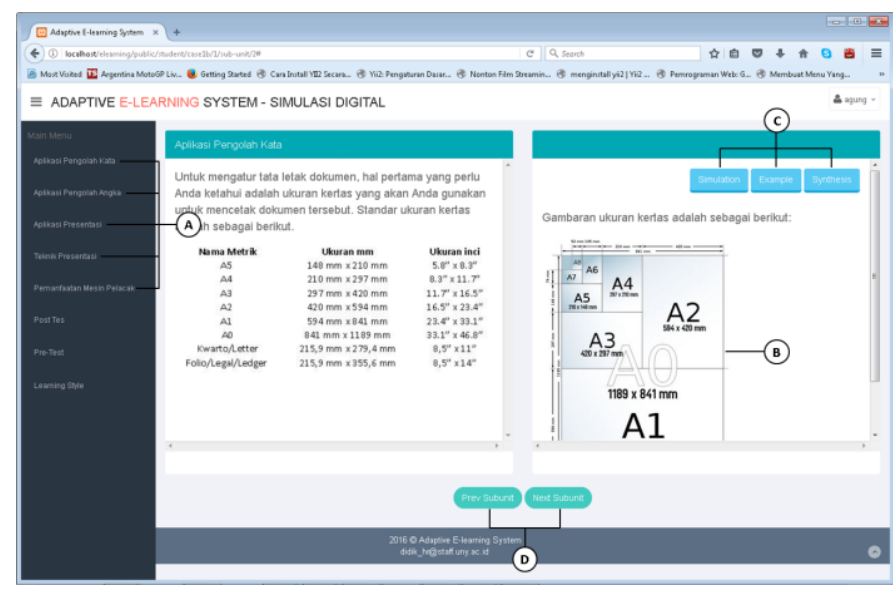

Fig. 9. User interface for example test case 1

The explanation regarding the figure above is as follows:

A. Since the score of the pre-test is lower than the standard grade set up by the instructor for each unit, all the unit links appear. For the sequential type, the menu shows only the unit links.

B. For the visual type, it shows visual media such as pictures.

C. For the active and sensing types, the Simulation, Example, and Synthesis buttons will be shown.

D. The Prev and Next buttons are shown for the sequential learner type.

\section{B. Example Test Case 2}

The results of the learning style questionnaire and pre-test are as follows:

- The learning style is reflective-intuitive-verbal-global

- The result of the pre-test indicates that the student score in Unit 5 exceeds the standard grade, but the results for Units 1, 2, 3, and 4 are lower than the standard grade. This means that the student has achieved competency for Unit 5 and does not need to learn Unit 5 content. However, for Units 1, 2, 3, and 4, he/she is not competent enough and should take the lesson.

Fig. 10 and Fig. 11 show the interface of the adaptive elearning system, which changes automatically when giving the input as described for example test case 2 . 


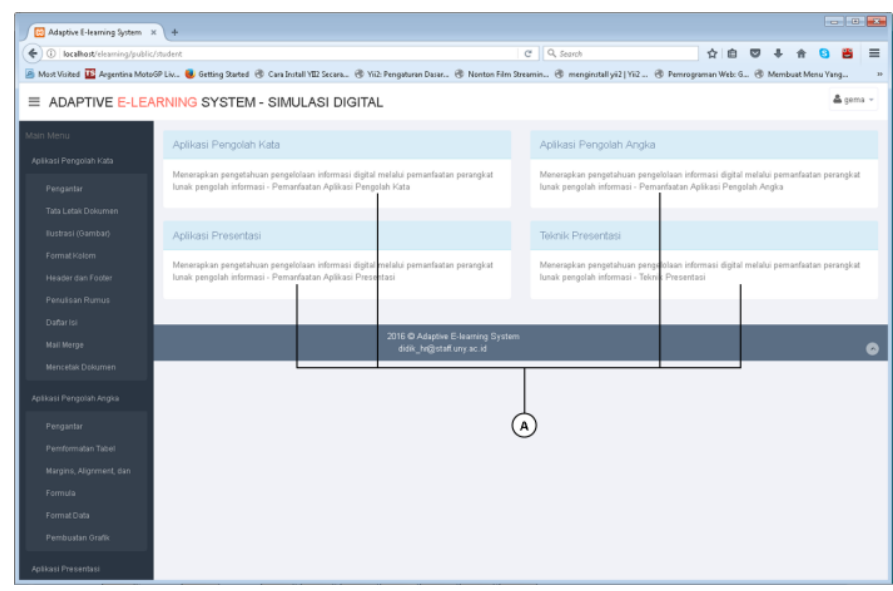

Fig. 10. First page of example test case 2

The explanation regarding the figure above is as follows:

A. For the global type, all units and a brief explanation of each unit are displayed. Four units are displayed because the student is already competent in Unit 5 , indicated by the pre-test score.

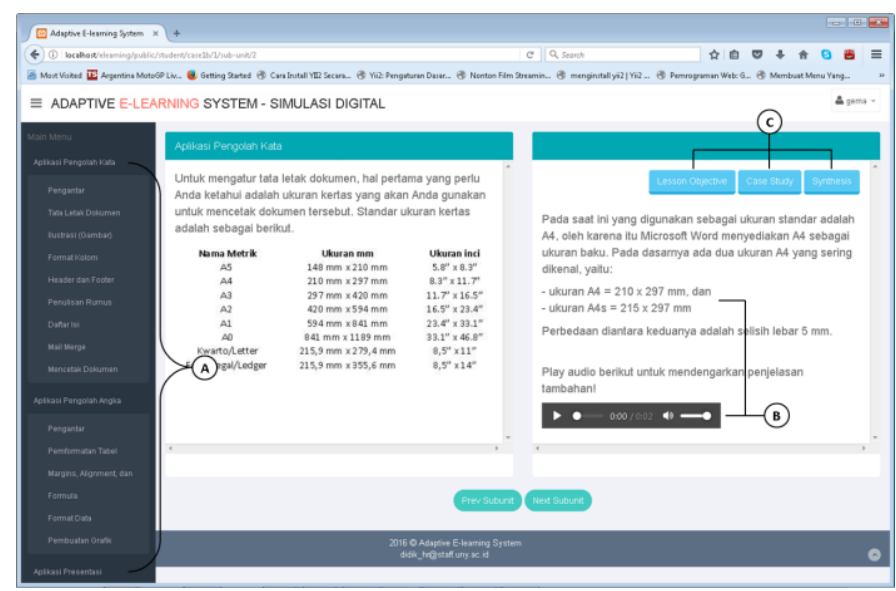

Fig. 11. User interface of example test case 2

The explanation regarding the figure above is as follows:

A. For the global type, all unit and sub-unit links are displayed.

B. For the verbal type, the information is provided in text and audio formats.

C. For the reflective and intuitive type, the Lesson Objective, Case Study, and Synthesis buttons are shows.

TABLE IV. FUNCTIONAL TEST RESULTS

\begin{tabular}{|c|c|c|c|c|c|c|c|c|c|c|}
\hline \multirow{3}{*}{$\begin{array}{l}\text { Test } \\
\text { Case }\end{array}$} & \multicolumn{9}{|c|}{ Combinational Input } & \multirow{3}{*}{ Functional Test Result } \\
\hline & \multicolumn{5}{|c|}{ Pre-Test } & \multicolumn{4}{|c|}{ Learning Style } & \\
\hline & Unit 1 & Unit 2 & Unit 3 & Unit 4 & Unit 5 & Dimension 1 & Dimension 2 & Dimension 3 & Dimension 4 & \\
\hline 1 & Fail & Fail & Fail & Fail & Fail & Active & Sensing & Visual & Sequential & The system responds as designed \\
\hline 2 & Pass & Fail & Fail & Fail & Fail & Active & Sensing & Visual & Global & The system responds as designed \\
\hline 3 & Fail & Pass & Fail & Fail & Fail & Active & Sensing & Verbal & Sequential & The system responds as designed \\
\hline 4 & Fail & Fail & Pass & Fail & Fail & Active & Sensing & Verbal & Global & The system responds as designed \\
\hline 5 & Fail & Fail & Fail & Pass & Fail & Active & Intuitive & Visual & Sequential & The system responds as designed \\
\hline 6 & Fail & Fail & Fail & Fail & Pass & Active & Intuitive & Visual & Global & The system responds as designed \\
\hline 7 & Pass & Fail & Fail & Fail & Fail & Active & Intuitive & Verbal & Sequential & The system responds as designed \\
\hline 8 & Fail & Pass & Fail & Fail & Fail & Active & Intuitive & Verbal & Global & The system responds as designed \\
\hline 9 & Fail & Fail & Pass & Fail & Fail & Reflective & Sensing & Visual & Sequential & The system responds as designed \\
\hline 10 & Fail & Fail & Fail & Pass & Fail & Reflective & Sensing & Visual & Global & The system responds as designed \\
\hline 11 & Fail & Fail & Fail & Fail & Pass & Reflective & Sensing & Verbal & Sequential & The system responds as designed \\
\hline 12 & Pass & Fail & Fail & Fail & Fail & Reflective & Sensing & Verbal & Global & The system responds as designed \\
\hline 13 & Fail & Pass & Fail & Fail & Fail & Reflective & Intuitive & Visual & Sequential & The system responds as designed \\
\hline 14 & Fail & Fail & Pass & Fail & Fail & Reflective & Intuitive & Visual & Global & The system responds as designed \\
\hline 15 & Fail & Fail & Fail & Pass & Fail & Reflective & Intuitive & Verbal & Sequential & The system responds as designed \\
\hline 16 & Fail & Fail & Fail & Fail & Pass & Reflective & Intuitive & Verbal & Global & The system responds as designed \\
\hline
\end{tabular}

\section{Functional Test Result}

Sixteen combinations of knowledge test and learning style preference results were administered in the system as input tests. In each input test conducted, the behavior of the system was observed to determine whether it responded as designed or not. The results of the visual observation of the system's user interface are reported in Table IV.

\section{DISCUSSION AND CONCLUSION}

The results of the functional test showed that the proposed adaptive e-learning system could react by changing the user interface automatically based on different inputs for learning style and initial student knowledge. Two parameters were input into the system. The first parameter is the initial knowledge of the students, measured by the pre-test on the five units. If the score from the pre-test in one unit matched with or exceeded the standard grade set up by the teacher, this means that the student passes for that unit. If the score did not satisfy the standard grade, the student failed for the unit. These conditions influence the appearances of the links in the menu area. Using the link hiding method, when the state is 'pass', then the link for the unit will disappear; when the state is 'fail', then the link will show up. The performance of the link hiding method in this test was successful. 
Another parameter input performed in this study is the student's learning style. For the sequential-global dimension, there are two possibilities; one is the sequential type learner and the other is the global type. In the sequential mode, the menu area shows only the unit links. In this mode, the direct guidance method was applied in the interface by installing the 'prev' and 'next' button to navigate within the learning environment. In the global mode, both the unit and sub-unit links will appear. In this case, the link hiding strategy is used again and performed as proposed in the user interface design.

The interface evaluation regarding the visual-verbal dimension revealed that the system could modify the interface adapt to both visual and verbal learners. In the visual condition, the learning material was presented in visual form (picture, video, animation), while in the verbal condition, it was presented by text and audio (verbal form). The concept of 'adaptation in presentation' has been well demonstrated in these conditions.

For both the active-reflective and sensing-intuitive dimensions, the system behaved as designed by showing or hiding the additional buttons as formulated in the set of rules listed in Table II. When the button was clicked for further testing, the new window appeared and the additional information was presented successfully. For the active learner, the additional material in the following learning objects (simulation, example, and synthesis) was presented. For the reflective learner, lesson objectives and case studies were provided. For the sensing type, the learner benefitted from simulation and example learning resources, while for the intuitive type, the synthesis, lesson objectives, and case study resources were successfully provided by the system.

Although functional test revealed that the system could perform as designed, the adaptive e-learning system still needs further improvement. A limitation of this study is that the functional test was performed by only a single user at one time. The performance of the system when it is accessed by many users simultaneously has not been tested yet. For future work, the developed prototype can be used in a real situation in a classroom setting with various students' preferences. This situation could reveal the technical performance of the system when accommodating many students at the same time. It also can show the extent to which the system can serve as a beneficial tool that helps students master certain topics in the learning process.

\section{ACKNOWLEDGMENT}

This work was supported by IGSP-DAAD (Indonesian Germany Scholarship Program - Deutscher Akademischer Austauschdienst) Scholarship.

\section{REFERENCES}

[1] P. Brusilovsky, "Methods and techniques of adaptive hypermedia," User modeling and user-adapted interaction, vol. 6, pp. 87-129, 1996.

[2] V. Shute and B. Towle, "Adaptive e-learning," Educational psychologist, vol. 38, pp. 105-114, 2003.

[3] M. Jevremović and Z. Vasić, "Adaptive e-learning," Acta facultatis medicae Naissensis, vol. 27, 2010.
[4] Z. Melicherikova and A. Bušíková, "Adaptive E-learning-A tool to overcome disadvantages of E-learning," in Emerging eLearning Technologies \& Applications (ICETA), 2012 IEEE 10th International Conference on, 2012, pp. 263-266.

[5] F. Kareal and J. Klema, "Adaptivity in e-learning," Current Developments in Technology-Assisted Education, vol. 1, pp. 260-264, 2006.

[6] R. Dunn, "Understanding the Dunn and Dunn learning styles model and the need for individual diagnosis and prescription," Reading, Writing, and Learning Disabilities, vol. 6, pp. 223-247, 1990.

[7] D. Rita and K. Dunn, "Learning Styles/Teaching Styles: Should They••• Can They... Be Matched," Educational leadership, 1993.

[8] D. A. Kolb, "Learning styles inventory," The Power of the 22 Matrix, p. 267, 2000.

[9] P. Honey and A. Mumford, "The manual of learning styles, 3rd," Maidenhead: Peter Honey, 1992.

[10] N. Fleming and C. Mills, "VARK: A Guide to Learning Styles. 2001," Last accessed on, vol. 30, 2010.

[11] S. Riechmann, "The Grasha-Riechmann student learning style scales: Research findings and applications," Student learning styles and brain behavior, pp. 81-86, 1982.

[12] K. C. Briggs, Myers-Briggs type indicator: Consulting Psychologists Press Palo Alto, CA, 1976.

[13] R. M. Felder and L. K. Silverman, "Learning and teaching styles in engineering education," Engineering education, vol. 78, pp. 674-681, 1988.

[14] R. J. Kapadia, "Teaching and learning styles in engineering education," in Frontiers in Education Conference, 2008. FIE 2008. 38th Annual, 2008, pp. T4B-1-T4B-4.

[15] M. S. Zywno, "A contribution to validation of score meaning for FelderSoloman's index of learning styles," in Proceedings of the 2003 American Society for Engineering Education annual conference \& exposition, 2003, pp. 1-5.

[16] D. P. Hunt, "The concept of knowledge and how to measure it," Journal of intellectual capital, vol. 4, pp. 100-113, 2003.

[17] G. Pask, "Review of conversation theory and a protologic (or protolanguage), Lp," Educational Technology Research and Development, vol. 32, pp. 3-40, 1984.

[18] D. Sutton, "What is knowledge and can it be managed?," European Journal of Information Systems, vol. 10, pp. 80-88, 2001.

[19] F. Mampadi, S. Y. Chen, G. Ghinea, and M.-P. Chen, "Design of adaptive hypermedia learning systems: A cognitive style approach," Computers \& Education, vol. 56, pp. 1003-1011, 2011.

[20] F. Lazarinis, S. Green, and E. Pearson, "Creating personalized assessments based on learner knowledge and objectives in a hypermedia Web testing application," Computers \& Education, vol. 55, pp. 1732$1743,2010$.

[21] P. De Bra, P. Brusilovsky, and G.-J. Houben, "Adaptive hypermedia: from systems to framework," ACM Computing Surveys (CSUR), vol. 31, p. 12, 1999.

[22] P. Brusilovsky, "Adaptive navigation support: From adaptive hypermedia to the adaptive web and beyond," PsychNology Journal, vol. 2, pp. 7-23, 2004.

[23] P. Brusilovsky, "Adaptive navigation support," The adaptive web, pp. 263-290, 2007.

[24] C. Carmona, G. Castillo, and E. Millán, "Discovering student preferences in e-learning," in Proceedings of the international workshop on applying data mining in e-learning, 2007, pp. 33-42.

[25] C. A. Carver, R. A. Howard, and W. D. Lane, "Enhancing student learning through hypermedia courseware and incorporation of student learning styles," IEEE transactions on Education, vol. 42, pp. 33-38, 1999.

[26] P. Q. Dung and A. M. Florea, "Adaptation To Learners' Learning Styles In A Multi-Agent E-Learning System," Internet Learning, vol. 2, p. 4, 2015.

[27] A. L. Franzoni, S. Assar, B. Defude, and J. Rojas, "Student learning styles adaptation method based on teaching strategies and electronic 
media," in Advanced Learning Technologies, 2008. ICALT'08. Eighth IEEE International Conference on, 2008, pp. 778-782.

[28] R. S. Pressman, Software engineering: a practitioner's approach: Palgrave Macmillan, 2005.

[29] L. Williams, "Testing overview and black-box testing techniques," Retrieved Agustus, vol. 12, p. 2015, 2006.
[30] L. Luo, "Software testing techniques," Institute for software research international Carnegie mellon university Pittsburgh, PA, vol. 15232, p. 19, 2001.

[31] J. Radatz, A. Geraci, and F. Katki, "IEEE standard glossary of software engineering terminology," IEEE Std, vol. 610121990, p. 3, 1990. 